\title{
Framing Teaching for Common Core Literacy Standards: SOAR Teaching Frames ${ }^{\mathrm{TM}}$ for Literacy
}

\author{
Susan O'Hara \\ University of California, Davis, USA
}

\author{
Robert Pritchard \\ EPF for teaching, USA
}

\begin{abstract}
This article describes the development of the Strategic Observation and Reflection (SOAR) Teaching Frames ${ }^{\mathrm{TM}}$ for Literacy and associated rubrics, which are tools for positioning learning and professional growth at the center of teacher effectiveness and evaluation systems. A first phase in the work has been to identify and articulate a set of high impact practices that support implementation of Common Core State Standards (CCSS) and demonstrate growth toward the California Standards for the Teaching Profession. These practices emerged from analyses of data from a number of studies of expert recommendations, observations of classroom instruction, existing instructional practice rubrics with established reliability and validity, and an extensive review of the research literature on effective literacy instruction. The data from these studies pointed to the essential relationships between high leverage essential practices and how they interconnect in effective classroom instruction. To show the interconnectedness of the practices, we have organized them into what we call Essential Practice Frames. The purpose of the process was to offer teachers and administrators who are currently implementing the CCSS a suite of tools that can be used for a variety of purposes: (1) informal or guided self-assessment of teaching practices; (2) site and district based professional learning initiatives; and (3) formal evaluation of teaching practices.
\end{abstract}

Keywords: Strategic Observation and Reflection (SOAR), essential teaching practices, essential practice frames, instructional capacity building, teacher driven professional learning

California's public education system opened the door to two significant innovations during 2009 and 2010 with ramifications for the professionalization of teaching. First, in 2009 the Commission on Teacher Credentialing (CTC) and the California Department of Education (CDE) set forth expectations for California teachers by way of six standards grounded in a "developmental and holistic vision of teaching", standards which apply to teachers of all grade levels and all disciplinary backgrounds (Commission on Teacher Credentialing, 2009). Throughout the California Standards for the Teaching Profession (CSTP) document, terms like "learning communities" and "professional communities" are reiterated, highlighting the essential role of collaboration, communication, and shared understanding among teachers and other stakeholders in effective schools. In addition, pointing out the necessity of "...a common language and a vision of the scope and complexity of the profession by which all teachers can define and develop their practice" (p. 1). A core assumption in California's vision of teaching is the idea that "...teachers are never 'finished' as professional

Susan O'Hara, Ph.D., Resourcing Excellence in Education (REEd), University of California, Davis.

Robert Pritchard, Ph.D., EPF for teaching. 
learners" (p. 2), that individual development unfolds in a professional community with experience and is profoundly, reciprocally shaped by self-assessment and reflective analysis and by the values, expectations, and beliefs of that community.

The second innovation in California, namely the State Board of Education's adoption of the California Common Core State Standards (CCSS) in 2010, has taken center stage in the day-to-day work of professionals in schools with unparalleled force. These standards articulate what students should be able to do by the end of high school, in order to be college and career ready. For example, the ELA Standards demand a greater balance between reading informational and literary texts, and stress the use of text-based evidence to support argumentation in writing and speaking. The Anchor Literacy Standards require students to engage in disciplinary discussions, identify and use evidence to support claims, and develop and use appropriate disciplinary language. Just as the CSTPs emerge from a view of teachers as reflective professionals obligated to make their own decisions about how they will teach in light of the needs of their particular students, the CCSS purpose fully did not prescribe what teachers should say or door enactor assign in their classrooms or schools.

The intersection of the vision of professional teaching in the CSTPs and the expectations for teachers as reflective practitioners in the CCSS is plain to see. But where can any educational professional find answers to questions like these: What does the practice of a particular teacher at an initial level look like in engaging and supporting all students in learning (CSTP1) to develop arguments to support claims using relevant and sufficient evidence (CCSS Writing Anchor 1)? How does the practice of this particular teacher at the initial level differ from that of a highly developed teacher? How do these signature practices change as they emerge across the continuum of teaching? What do they look like concretely once they have developed through sustained reflective analysis and professional development? We believe that questions like these are at the heart of successful CCSS implementation.

\section{Theory of Change}

We adopted a multi-tier strategy for supporting implementation of the CCSS through systems of professional growth. This multi-tier strategy is aligned with a research based theory of change and attends to three key design principles for building instructional capacity: target the instructional shifts needed for CCSS to provide a laser-like focus for the work and drive learning outcomes for all students; cultivate local teacher community in driving instructional change; and create the conditions necessary for continuous improvement through systems of professional growth.

\section{Targeting the Instructional Shifts Needed for CCSS Implementation}

Our first design principle addresses the need to focus any instructional improvement process on a set of targeted high leverage practices (Ball, 2013; Fogo, 2011; O'Hara, Pritchard, \& Zwiers, 2014; Windshitl, Thompson, \& Braaten, 2011). To have the significant impact on student outcomes, as articulated in the CCSS, we must focus on the improvement of a set of high leverage instructional practices. Essential practice frames, which we developed as part of our work with Local Education Agencies on teacher evaluation, can be used as a lever to effect change in classroom practice. This approach is predicated on the importance of providing instructional leaders and teachers with a common language around the instructional shifts needed for CCSS implementation, and with time for deliberate practice of new instructional moves that are aligned with CCSS. 
We envision these essential practice frames as the nexus between the lofty aims of the CSTPs and the concrete expectations for students of the CCSS, which currently are stand-alone frameworks.

\section{IPLS Network: Theory of Change}

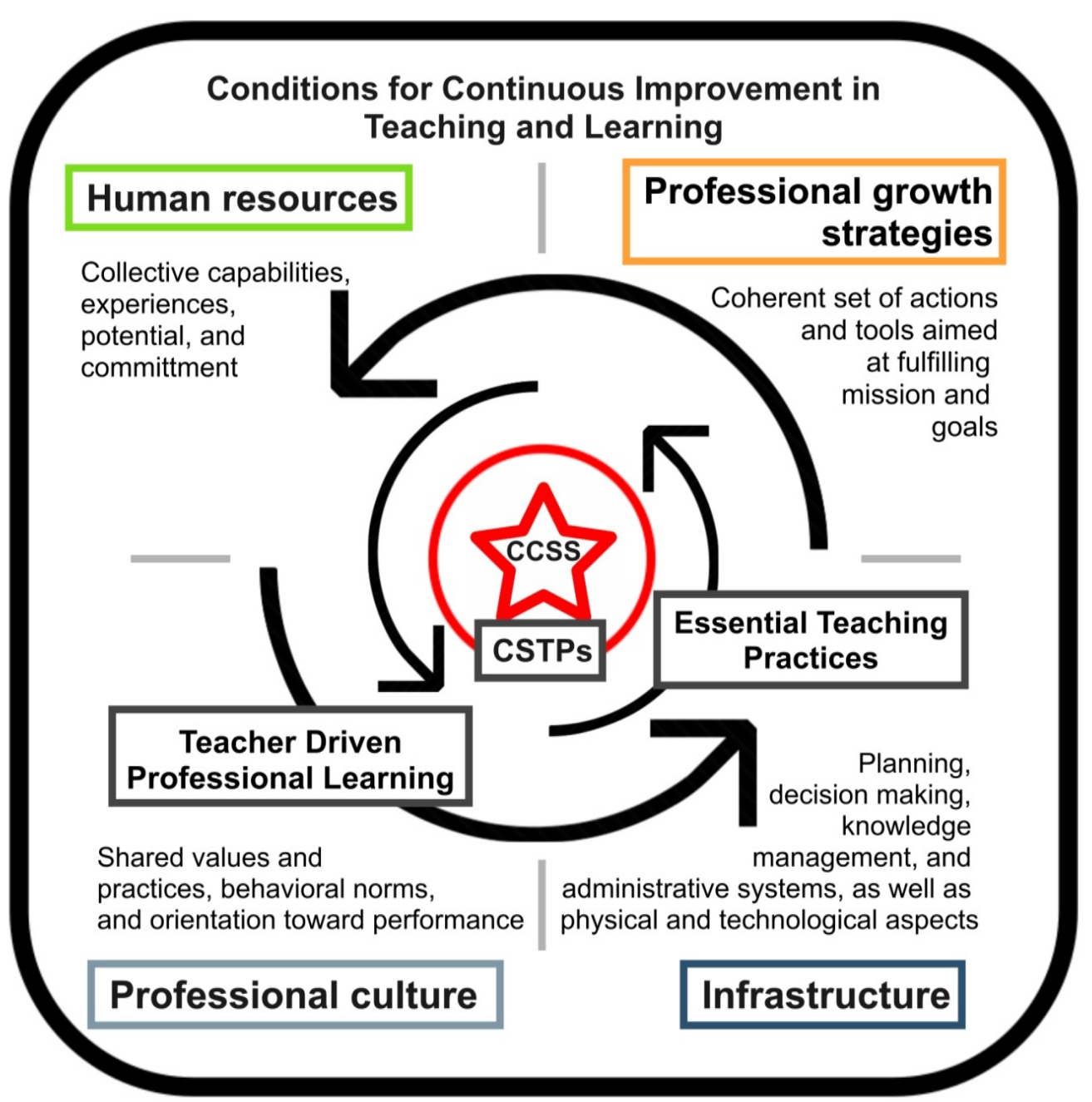

AIM: To create a nexus between expectations for students (Common Core State Standards) and expectations for teaching (California Standards for the Teaching Profession), which are currently stand-alone frameworks

\section{Figure 1. IPLS network: Theory of change.}

\section{Teacher Driven Professional Learning}

The second key design principle for this project concerns the importance of local teacher community in driving instructional change. The work on teacher learning community suggests the importance of engaging the collective energies of teachers in addressing issues of reform (Little, 1982; McLaughlin \& Talbert, 2001; Sullivan \& Westover, 2015). Research on professional community suggests the importance of collegial inter-change and experimentation, shared decision-making, and sense-making in learning opportunities for 
teachers aimed at instructional change (Kazemi \& Franke, 2004; Little, 1982; McLaughlin \& Talbert, 2001). These principles regarding teacher driven reform guide the development of our approach, in which teachers play a key role in deciding how to focus the professional development and work together as a collective to improve practice as they implement CCSS. In this professional learning community, individual teachers might use the essential practice frames and associated rubrics for self-assessment and reflective analysis, leading to the development of individual professional development goals. Groups of teachers would use them to focus teacher inquiries or self-studies for grade-level or program improvement directly related to CCSS implementation. Principals could ask the entire faculty at a school to self-assess using the frames and associated rubrics and then use the results to target CCSS-relevant professional learning activities tailored to the particular faculty group. Superintendents could use them in a similar manner across a whole district. Evaluations of professional learning strategies and activities undertaken to build capacity in one or another area of the CCSS-CSTP intersection could be collected and studied to help all districts discern which activities targeted for which areas appear to be most useful.

\section{Building Capacity to Develop Sustainable Learning}

The third design principle focuses on the importance of building the organizational infrastructure and conditions to grow, sustain, and spread the use of essential practices that support individual and collective professional growth. Jaquith $(2009 ; 2012)$ suggests that instructional capacity can be built through a generative cycle of resource identification and use. Jaquith's model suggests that successful CCSS implementation will require an attention to four dimensions of organizational change: (1) Increase in human resources: Collective capabilities, instructional knowledge, experience, potential, and commitment; (2) Enacted professional growth strategies: Coherent set of actions and tools aimed at fulfilling instructional mission and goals; (3) Cultivated professional culture within schools and between schools and families: Greater levels of collegiality, trust, and willingness to participate in continuous instructional improvement efforts; and (4) Supporting infrastructure: Increase in reliance and use of integrated approaches for supporting professional growth and performance.

The first step in our theory of change, which focuses on the identification of a set of essential instructional practices (see Table 1) and the development of essential practice frames (see Table 2) that drive student learning for CCSS, is the focal point of this article.

Table 1

SOAR Teaching Practices for Literacy

\begin{tabular}{|c|c|c|c|}
\hline \multirow{6}{*}{$\begin{array}{l}\text { High-Impact } \\
\text { Practices }\end{array}$} & \multicolumn{3}{|c|}{ Acquisition of Disciplinary Language } \\
\hline & \multicolumn{3}{|c|}{ Disciplinary Thinking Processes } \\
\hline & \multicolumn{3}{|l|}{ Disciplinary Perseverance } \\
\hline & \multicolumn{3}{|c|}{ Disciplinary Communication } \\
\hline & \multicolumn{3}{|l|}{ Disciplinary Discussions } \\
\hline & \multicolumn{3}{|c|}{ Disciplinary Uses of Evidence } \\
\hline $\begin{array}{l}\text { Cross-Cutting } \\
\text { Practices } \\
\end{array}$ & $\begin{array}{l}\text { Promoting a Culture of } \\
\text { Disciplinary Learning } \\
\end{array}$ & $\begin{array}{l}\text { Fostering Metacognition for } \\
\text { Disciplinary Learning }\end{array}$ & $\begin{array}{l}\text { Monitoring and Guiding } \\
\text { Disciplinary Learning }\end{array}$ \\
\hline $\begin{array}{l}\text { Foundational } \\
\text { Practice }\end{array}$ & \multicolumn{3}{|c|}{ Designing Instruction for Disciplinary Thinking and Understanding } \\
\hline
\end{tabular}


Table 2

Sample SOAR Teaching Frame ${ }^{\mathrm{TM}}$ for Literacy

\begin{tabular}{|l|l|l|l|}
\hline $\begin{array}{l}\text { High-Impact } \\
\text { Practices }\end{array}$ & $\begin{array}{l}\text { Disciplinary Discussions } \\
\text { Build disciplinary conversation skills } \\
\text { Provide multiple, extended, and supported opportunities for students to engage in disciplinary discussions }\end{array}$ \\
\hline & $\begin{array}{l}\text { Promoting A Culture } \\
\text { of Disciplinary Learning }\end{array}$ & $\begin{array}{l}\text { Fostering Metacognition for } \\
\text { Disciplinary Learning }\end{array}$ & $\begin{array}{l}\text { Monitoring and Guiding } \\
\text { Disciplinary Learning }\end{array}$ \\
$\begin{array}{l}\text { Eross-Cutting } \\
\text { Practices }\end{array}$ & $\begin{array}{l}\text { Enact and refer to norms of } \\
\text { interaction that enable all students } \\
\text { to participate and take risks } \\
\text { Establish high expectations and } \\
\text { maintain the intellectual rigor of } \\
\text { classroom activities }\end{array}$ & $\begin{array}{l}\text { laceses students are expected to } \\
\text { use in support of disciplinary } \\
\text { learning } \\
\text { Deconstruct metacognitive } \\
\text { processes that support disciplinary } \\
\text { learning }\end{array}$ & $\begin{array}{l}\text { Monitor learning and adjust } \\
\text { instruction, supports, and } \\
\text { disciplinary tasks to meet student } \\
\text { needs } \\
\text { Provide written and/or oral } \\
\text { feedback during lessons to promote } \\
\text { disciplinary learning }\end{array}$ \\
\hline $\begin{array}{l}\text { Foundational } \\
\text { Practice }\end{array}$ & $\begin{array}{l}\text { Designing Instruction for Disciplinary Thinking and Understanding } \\
\text { Set disciplinary learning targets that are aligned with ELA/Literacy CCSS and the target high-impact } \\
\text { practice } \\
\text { Structure and connect tasks that support the learning targets } \\
\text { Design supports to help students meet the disciplinary language demands of texts and task }\end{array}$ \\
\hline
\end{tabular}

\section{Identifying Essential Teaching Practices}

Defining "professional teaching" by way of the California Standards for the Teaching Profession (CSTP), and defining "student learning" according to the grade-by-grade expectations of the CA ELA/ELD Framework, our project team developed a set of the Strategic Observation and Reflection (SOAR) Teaching Frames ${ }^{\mathrm{TM}}$ for the ELA and Anchor Literacy Standards and for the Mathematics Standards. The SOAR ${ }^{\text {TM }}$ Teaching Frames for Literacy and associated rubrics index the stage of development of classroom teachers at four levels: no evidence, limited evidence, acceptable evidence, and strong evidence. These specific rubrics apply to ELA and Anchor Literacy Standards as per CCSS (grades Tk-2 and grades 3-12). Other rubrics that have been developed as part of this ongoing work include: SOAR Teaching Frames ${ }^{\mathrm{TM}}$ for Math TK-12; and Academic Language and Literacy in Every Subject (ALLIES Teaching Frames ${ }^{\mathrm{TM}}$ ) TK-12.

The development of these rubrics has been guided by the question: Which practices are most essential and highest leverage for supporting the CCSS and demonstrating progress toward the CSTP? In developing the SOAR Teaching Frames ${ }^{\mathrm{TM}}$ and ALLIES Teaching Frames, and corresponding rubrics, we sought to avoid the following: (1) developing so many practices that the essential practices that drive student learning get lost; (2) developing a discrete set of practices with no articulation of how the practices are interconnected in instruction; and (3) articulating the practices at a "grain size" that is either too small or too large to foster professional growth.

The Essential Practice Frames (EPFs) ${ }^{\mathrm{TM}}$ and associated rubrics are the result of more than six years of research and development. The purpose of the frames is to offer teachers, coaches and administrators, who are currently implementing new College and Career Readiness Standards including the CCSS, a suite of tools that can be used for a variety of purposes: (1) informal or guided self-assessment of teaching practices; (2) site- and district-based professional growth initiatives; (3) formative assessment of teaching practices; and (4) teacher evaluation. Our research and development suggest that these frames are powerful tools for driving both teacher and student growth. Our team of educational researchers and practitioners engaged in systematic research to 
identify the essential practices that teachers can use to drive language and literacy learning across disciplines as articulated in the CCSS ELA and Anchor Literacy Standards.

The practices articulated in the SOAR Teaching Frames ${ }^{\mathrm{TM}}$ for Literacy emerged from analyses of data from Delphi Panel studies of expert consensus on disciplinary literacy instruction across content areas (Brisk \& Proctor, 2012; Echevarria, Richards-Tutor, Chinn, \& Ratleff, 2011; Grossman, Loeb, Cohen, \& Wyckoff, 2013), video observations of classroom instruction (O’Hara, Pritchard, \& Zwiers, 2014), existing instructional practice rubrics with established reliability and predictive validity (Bill \& Melinda Gates Foundation, 2014; Danielson, 2013; Grossman, Cohen, \& Brown, 2014; O'Hara et al., in press), and an extensive review of the research literature on effective literacy instruction (Baker et al., 2014; Fisher, Frey, \& Lapp, 2012; Nagy \& Townsend, 2012; Uccelli, Galloway, Barr, Meneses, \& Dobbs, 2015). The SOAR ${ }^{\mathrm{TM}}$ Teaching Frames for Literacy is a 21-item scoring protocol evaluating ten essential practices critical to the teaching of CCSS ELA and Anchor Literacy Standards. The results of our research revealed both a set of practices essential for CCSS, as well as a framework for how these practices are interconnected during instruction, which we call Essential Practice Frames.

\section{Essential Practice Descriptions}

At the top of each of the six Essential Practice Frames are high-impact practices that our research identified as having high potential to drive student learning as articulated in the CCSS ELA and Anchor Literacy Standards. The six high-impact practices that we have identified are:

(1) Acquisition of Disciplinary Language: This practice focuses on structuring, strengthening, and supporting the acquisition and use of the language needed to participate in knowledge construction and disciplinary tasks. Disciplinary language has three distinctive features: vocabulary, syntax, and discourse (August et al., 2014; Cook, Boals, \& Lundberg, 2011; Nagy \& Townsend, 2012).

(2) Disciplinary Thinking Processes: This practice focuses on structuring, strengthening, and supporting disciplinary thinking skills to practice and deepen comprehension, content knowledge, and disciplinary language (Fogo, 2011; Murphy, Rowe, Ramani, \& Silverman, 2014; Schoenfeld, 2011).

(3) Disciplinary Perseverance: This practice focuses on structuring, strengthening, and supporting students' ability to persevere, which includes setting long-term goals, accepting ambiguity, sustaining stamina, and adjusting approaches (Beers \& Probst, 2013; Marzano \& Heflebower, 2011; Zwiers, O’Hara, \& Pritchard, 2014b).

(4) Disciplinary Communication: This practice focuses on structuring, strengthening, and supporting the quantity and quality of students' oral and written output using academic language (Bernabei \& Reimer, 2013; Zwiers, O’Hara, \& Pritchard, 2014a; Zwiers et al., 2014c).

(5) Disciplinary Discussions: This practice focuses on structuring, strengthening, and supporting students' ability to engage in student-to-student disciplinary discussions. Disciplinary discussions can consist of face-to-face interactions, online dialogues, and written conversations (Kazemi \& Hintz, 2014; Zwiers \& Crawford, 2011; Zwiers, O’Hara, \& Pritchard, 2014d).

(6) Disciplinary Uses of Evidence: This practice focuses on structuring, strengthening, and supporting uses of multiple forms of evidence in disciplinary writing and speaking (Cummins, 2013; Fisher \& Frey, 2014; Kibler, Walqui, \& Bunch, 2015).

High-impact practices are not effective without the three cross-cutting practices. These include Promoting 
a Culture of Disciplinary Learning, Fostering Metacognition for Disciplinary Learning, and Monitoring and Guiding Disciplinary Learning.

(1) Promoting a Culture of Disciplinary Learning: This practice focuses on the process of developing and enacting norms of interaction that promote a culture of disciplinary learning and intellectual rigor as well as on how the teacher establishes high expectations and fosters in all students the willingness to participate in tasks and take risks (Brophy, 2010; Finley, 2015; Jennings \& Greenberg, 2008).

(2) Fostering Metacognition for Disciplinary Learning: This practice focuses on the degree to which a teacher visibly enacts and deconstructs metacognitive processes and strategies that foster students' metacognitive knowledge. Examples of metacognitive processes include: self-monitoring, self-assessing, self-questioning, and selection of strategies (Marzano \& Heflebower, 2011; Schoenbach, Greenleaf, \& Murphy, 2012).

(3) Monitoring and Guiding Disciplinary Learning: This practice focuses on how effectively a teacher monitors and guides the disciplinary learning throughout each task and the lesson as a whole, as well as adjusts and supports disciplinary tasks to meet the current needs of all students in the classroom. This practice also includes providing feedback and gradually removing supports to foster students' ability to work flexibly and independently (Marzano, Yanoski, Hoegh, \& Simms, 2013; Wiggins, 2012).

The cross-cutting and high-impact practices are not effective without the foundational practice.

Designing Instruction for Disciplinary Thinking and Understanding: This practice focuses on the design of lessons and learning tasks to promote disciplinary learning and support the target, high-impact practice. This practice also focuses on how clearly and directly the teacher aligns disciplinary learning targets with the lesson's texts and tasks, and enables students to meet the disciplinary concepts and language demands of tasks and texts (Marzano et al., 2013; Wilson, Sztajn, Edington, \& Myers, 2015; Zwiers et al., 2014b).

\section{Reliability and Validity}

To establish reliability, two procedures were used. We trained raters to score 40 videos on classroom practice using the newly developed SOAR ${ }^{\mathrm{TM}}$ protocol. The pilot data was analyzed and showed high generalizability $\left(\mathrm{E} \sigma^{2}=0.90\right)$, and high inter-rater reliability correlations, $r>0.91$. The Standards for Educational and Psychological Testing (APA, 1999) defines validity as "the degree to which evidence and theory support the interpretations of test scores" (p. 9). Three critical elements are established with this definition: theory, evidence, and interpretations. To establish the validity of a measurement tool, there must be a theoretical foundation. The Essential Practice Frames purport to reliably and accurately identify teacher practices that foster student practices related to the CCSS ELA and Anchor Literacy Standards. However, claims such as those outlined in the literature and stated here are merely claims, albeit research-based. Evidence is required to instantiate these claims (Kane, 2001). Data from Delphi studies of expert consensus, together with a series of expert convenings, were collected to support the validity claims made in support of the SOAR ${ }^{\mathrm{TM}}$ Teaching Frames.

\section{Operationalizing the SOAR ${ }^{\mathrm{TM}}$ Protocol}

We intend for this protocol to be used in several ways. First, we believe that it will support teachers in improving their teaching of disciplinary literacy and implementation of the CCSS. Having identified the practices that are most predictive of student growth, our team has developed a corresponding set of videos and 
materials to illustrate what these practices look like at different levels of enactment. In partnership with "Frontline Technologies" and "EPF for teaching", we have developed a calibration platform designed around the SOAR ${ }^{\mathrm{TM}}$ Teaching Practice Frames. This new calibration platform:

(1) provides a much needed nexus between the CCSS and CSTP;

(2) helps teachers and administrators drive student learning by focusing on a set of effective, integrated instructional practices for CCSS ELA and Anchor Literacy Standards;

(3) scaffolds professional learning opportunities for teachers in different grade spans (TK-2, 3-8 and 9-12) and across content areas (ELA, Math, Social Studies, Science).

This study identified essential instructional practices that drive student learning as articulated in the CCSS. Furthermore, the findings suggest a framework for how these essential practices are interconnected in effective disciplinary language and literacy teaching. We are currently using the protocol and corresponding online support materials in professional growth programs for teachers, coaches and instructional leaders in partner districts and schools across the state of California. Preliminary findings from this work support recent research on teacher professional development that suggests the need to identify and focus on core instructional practices in teacher preparation and professional development (Lampert, 2010; Windschitl, Thompson, \& Braaten, 2011). This framework provides a suite of powerful tools for supporting leaders', coaches', and teachers' adoption and enactment of these practices in their contexts. A calibration tool for the SOAR Teaching Frames for Math is currently under development.

\section{References}

APA. (1999). The Standards for Educational and Psychological Testing. Washington, D.C.: Author.

August, D., Branum-Martin, L., Cardenas-Hagan, E., Francis, D., Powell, J., Moore, S., \& Haynes, E. (2014). Helping ELLs meet the Common Core State Standards for literacy in science: The impact of an instructional intervention focused on academic language. Journal of Research on Educational Effectiveness, 7, 54-82.

Baker, S., Lesaux, N., Jayanthi, M., Dimino, J., Proctor, C. P., Morris, J., Gersten, R., Haymond, K., Kieffer, M. J., Linan-Thompson, S., \& Newman-Gonchar, R. (2014). Teaching academic content and literacy to English learners in elementary and middle school (NCEE 2014-4012). Washington, D.C.: National Center for Education Evaluation and Regional Assistance (NCEE), Institute of Education Sciences, U.S. Department of Education. Retrieved from http://ies.ed.gov/ncee/wwc/publications_reviews.aspx.

Ball, S. J. (2013). The education debate. Chicago: Policy Press.

Beers, K., \& Probst, R. (2013). Notice \& note: Strategies for close reading. Portsmouth, N.H.: Heinemann.

Bernabei, G., \& Reimer, J. (2013). Academic writing for serious learning. Thousand Oaks, C.A.: Corwin Literacy.

Bill \& Melinda Gates Foundation. (2014). Building trust in observations: A blueprint for improving systems to support great teaching. Seattle, W.A.: Author.

Brisk, M. E., \& Proctor, C. P. (2012). Challenges and supports for English language learners. In K. Hakuta, \& M. Santos (Eds.), Understanding language: Language, literacy, and learning in the content areas (pp. 115-122). Palo Alto, C.A.: Stanford University.

Brophy, J. (2010). Motivating students to learn (3rd ed.). New York, N.Y.: Routledge.

Commission on Teacher Credentialing. (2009). California Standards for the Teaching Profession. Sacramento, C.A.: Author.

Cook, H. G., Boals, T., \& Lundberg, T. (2011). Academic achievement for English learners: What can we reasonably expect? Phi Delta Kappan, 93(3), 66-69. Retrieved from http://intl.kappanmagazine.org

Cummins, S. (2013). Close reading of informational texts: Assessment-driven instruction in Grades 3-8. New York, NY: Guilford Press.

Danielson, C. (2013). The framework for teaching evaluation instrument. Princeton, N.J.: The Danielson Group.

Echevarria, J., Richards-Tutor, C., Chinn, V., \& Ratleff, P. (2011). Did they get it? The role of fidelity in teaching English learners. Journal of Adolescent \& Adult Literacy, 54(6), 425-434. Doi: 10.1598/JAAL.54.6.4. 
Finley, T. (2015). The science behind classroom norming. Edutopia, Retrieved from: http://www.edutopia.org/blog/establishing-classroom-norms-todd-finley

Fisher, D., \& Frey, N. (2014). Close reading and writing from sources. Newark, D.E.: International Reading Association.

Fisher, D., Frey, N., \& Lapp, D. (2012). Text complexity: Raising rigor in reading. International Reading Association: Newark, DE.

Fogo, B. (2011). Making and measuring the California history standards. Phi Delta Kappan, 92(8), 62-67.

Grossman, P., Cohen, J., \& Brown, L. (2014). Understanding instructional quality in English Language Arts: Variations in the relationship between PLATO and value-added by content and context. In T. Kane, K. Kerr, \& R. Pianta (Eds.). Designing teacher evaluation systems: New guidance from the Measures of Effective Teaching project. John Wiley \& Sons.

Grossman, P., Loeb, S., Cohen, J., \& Wyckoff, J. (2013). Measure for measure: The relationship between measures of instructional practice in middle school English Language Arts and teachers' value-added scores. American Journal of Education, 119(3), 445-470.

Jaquith, A. C. (2009). The creation and use of instructional resources: The puzzle of professional development. Retrieved from ERIC. (ED513238)

Jaquith, A. (2012). Building instructional capacity: A research brief. Retrievedfromhttp://tqsource.airws.org/webcasts/2012ELL/ Final_Research\%20Brief_Instructional\%20capacity\%20building.pdf

Jennings, P., \& Greenberg, M. (2008). The prosocial classroom: Teacher social and emotional competence in relation to student and classroom outcomes. Review of Educational Research, 79(1), 491-525.

Kane, M. (2001). Current concerns in validity theory. Journal of Educational Measurement, 38(4), 319-342.

Kazemi, E., \& Franke, M. L. (2004). Teacher learning in mathematics: Using student work to promote collective inquiry. Journal of Mathematics Teacher Education, 7(3), 203-235. doi:10.1023/B:JMTE.0000033084.26326.19

Kazwmi, E., \& Hintz, A. (2014). Intentional talk. Portland, M.E.: Stenhouse.

Kibler, A., Walqui, A., \& Bunch, G. (2015). Transformational opportunities: Language and literacy instruction for English language learners in the Common Core era in the United States. TESOL Journal, 6(1), 9-35. DOI: 10.10002/tesj.133

Lampert, M. (2010). Learning teaching in, from, and for practice: What do we mean? Journal of Teacher Education, 63(1-2), 21-34.

Little, J. W. (1982). Norms of collegiality and experimentation: Workplace conditions of school success. American educational research journal, 19(3), 325-340.

Marzano, R., \& Heflebower, T. (2011). Teaching \& assessing 21st Century skills. Centennial, C.O.: Marzano Research.

Marzano, R., Yanoski, D., Hoegh, J., \& Simms, J. (2013). Using common core standards to enhance classroom instruction and assessment. Centennial, C.O.: Marzano Research.

McLaughlin, M., \& Talbert, J. E. (2001). Professional communities and the work of high school teaching. Chicago: University of Chicago Press.

Murphy, P.K., Rowe, M., Ramani, G., \& Silverman, R. (2014). Retrieved fromhttp://link.springer.com/article/10.1007/s10648-01 4-9281-3\#page-2

Nagy, W., \& Townsend, D. (2012). Words as tools: Learning academic vocabulary as language acquisition. Reading Research Quarterly, 47(1), 91-108. DOI: 10.1002/RRQ.011

O'Hara, S., Pritchard, R., \& Zwiers, J. (2014). The academic language development program: A capacity-building approach to supporting secondary teachers of English learners. Proceedings of the Adult Education Research Conference, 2014, pp. 349-354, Harrisburg, P.A..

O'Hara, S., Pritchard, R., \& Zwiers, J. (in press). Academic language and literacy in every subject (ALLIES): A capacity building approach to supporting teachers in grades 4-8. In P. Proctor, A. Boardman, \& E. Hiebert (Eds.), English learners and emergent bilingualism in the common core era. New York, N.Y.: Guilford Press.

O'Hara, S., Pritchard, R., Pitta, D., and Webb, J. (in press). Implementing new technologies to support social justice pedagogy. In R. Papa, D. M. Eadens, \& D. M. Eadens, (Eds.), Social justice instruction: Empowerment on the chalkboard. Springer Publishing.

O'Hara, S., Zwiers, J., \& Pritchard, R. (2012). Framing the teaching of academic language: A research brief. (Webinar) National Comprehensive Center for Teacher Quality. Retrieved from http://www.tqsource.org/webcasts/2012ELL/

Pritchard, R., O'Hara, S., \& Zwiers, J. (2014). Using new technologies to engage and support English learners in mathematics classrooms. In D. Polly (Ed.) Cases on technology and common core mathematics standards (pp. 145-163). IGI Global. Hersey, P.A.. 
Pritchard, R., O'Hara, S., \&Zwiers, J. (in press). Framing the teaching of academic language to English learners: A Delphi study of expert consensus. TESOL Quarterly.

Schoenbach, R., Greenleaf, C., \& Murphy, L. (2012). Reading for understanding: How reading apprenticeship improves disciplinary learning. San Francisco, C.A.: Jossey-Bass.

Schoenfeld, A. (2011). Education: Learning to think in a discipline. Retrieved from http://gsi.berkeley.edu/gsi-guide-contents/learning-theory-research/think-discipline/

Sullivan, L., \& Westover, T. (2015.) In the driver's seat: Teacher-led model moves in the right direction. Journal of Staff Development, 36(3), 24-32.

Uccelli, P., Galloway, E., Barr, C., Meneses, A., \& Dobbs, C. (2015). Beyond vocabulary: Exploring cross-disciplinary academic-language proficiency and its association with reading comprehension. Reading Research Quarterly, 50(3), 337-356. DOI: $10.1002 /$ rrq.104.

Wiggins, G. (2012). Seven keys for effective feedback. Feedback for Learning, 70(1), 10-16.

Wilson, H. W., Sztajn, P., Edington, C., \& Myers, M. (2015). Teachers' uses of a learning trajectory in student-centered instructional practices. Journal of Teacher Education, 66(3), 227-244.

Windschitl, M., Thompson, J., \& Braaten, M. (2011). Ambitious pedagogy by novice teachers? Who benefits from tool-supported collaborative inquiry into practice and why? Teachers College Record, 113(7), 1311-1360. Retrieved fromhttp://www.tcrecord.org/Content.asp?contentid=16061

Zwiers, J., \& Crawford, M. (2011). Academic Conversations. Portland, M.E.: Stenhouse.

Zwiers, J., O'Hara, S., \& Pritchard, R. (2014a). Common Core Standards in diverse classrooms: Essential practices for developing academic language and disciplinary literacy. Portland, M.E.: Stenhouse.

Zwiers, J., O'Hara, S., \& Pritchard, R. (2014b). Cutting to the Common Core: Changing the playing field, part 1. Language Magazine: The Journal of Communication \& Education, 13(5), 24-27.

Zwiers, J., O'Hara, S., \& Pritchard, R. (2014c). Cutting to the Common Core: Changing the playing field, part 2. Language Magazine: The Journal of Communication \& Education, 13(6), 26-27.

Zwiers, J., O'Hara, S., \& Pritchard, R. (2014d). Conversing to fortify literacy, language, and learning. Voices from the Middle, 22(1), 10-14. 